\title{
The Pains of Sexual Abuse and the Efficacy of Psychotherapy in Treating Psychological Distress in a Sexual Abuse Victim
}

\author{
Dauda Akwai Saleh \\ Department of Psychology, Plateau State University Bokkos, Nigeria \\ Email: salehadkwai@yahoo.com
}

\begin{abstract}
This study investigates the pains of sexual abuse and the efficacy of psychotherapy in treating psychological distress in a 22 year old undergraduate student who was sexually abused between ages 7 and 9. Single case pre/post test experimental design utilizing a mixed method using qualitative and quantitative approach was utilized in this study. The study lasted for 13 sessions of psychotherapy. All data were manually analysed, client's raw scores were compared with the mean scores/cut-off points of instruments of data collection. Two research questions were answered in this study; Pre test result revealed that, based on SCL-90, participant had significant levels of psychological distress on 9 sub scales with the total score of 218 , depression had the highest score of 40, followed by anxiety with 31, Interpersonal sensitivity 29, Obsessive compulsive 23, Phobic anxiety 23, Psychoticism 21, Paranoid ideation 17, Neuroticism 11 and Hostility 10. On PCL- S, participant's score of 54 is significant for the diagnosis of posttraumatic stress disorder. The score of 28 on Beck Depression inventory indicate moderate level of depression. While on Beck Hopelessness scale, the score of 5 indicate mild level of hopelessness. Result of the second research question (post-test) after the 10 session of psychotherapy revealed that, participants scores on all instruments reduced; On SCL-90; only 3 subscales were significant with lower scores compared to results of pre test, Obsessive compulsive 21, Interpersonal sensitivity 17, and Paranoid ideation 16, with the total SCL-90 score of 100. On PCL- S participants score of 32 indicate absence of PTSD. Participant's score of 9 and 0 on Beck depression inventory and Beck Hopelessness scale falls within the normal/minimal levels of depression and hopelessness respectively. The researcher recommends that, parents and care givers should be cautions of those who take care of their wards and the child act right should be implemented in all states of the federation. There is the need for awareness in schools and among women groups on sexual abuse among children.
\end{abstract}

Keywords: Pains, sexual abuse, efficacy, psychotherapy, treating, psychological distress

\section{Introduction}

Child sexual abuse includes everything from fondling to oral, vaginal or anal penetration (KendallTackett, 2001). Child sexual abuse is defined as any sexual act between an adult and a minor, or between two minors, when one exerts power over the other (Townsend \& Rheingold, 2013). Child sexual abuse is a widespread form of child abuse that has remained the most under-reported. Much remain unknown of this act which often leaves victims traumatized with unsavoury memory that tends to affect their psychosocial development (Abdulkadir, Musa, Umar, Musa, Jimoh, \& Na'uzo, 2011). Both males and females are abused sexually, thus, Goldman and Goldman, (1988) reports that, $28 \%$ of girls and $9 \%$ of boys experience sexual experiences with adults. The mean age of the victims of the incidents reported was 9.8 years for girls and 10.3 years for boys. $24 \%$ of abusers were strangers compared with $76 \%$ known to the children. National Centre for Juvenile Justice (2001) reports that over $90 \%$ of sexual assault survivor's ages 12-17 were female. In eight out of 10 cases of rape, the victim knew the person who sexually assaulted them (Miller, Cohen, \& Wiersema, 1996). Therefore, Whealin, (2007) and Finkelhor, (2012) reports that, approximately 30\% of children who are sexually abused are abused by family members while about $60 \%$ are sexually abused by people the family trusts. Similarly, Abdulkadir et al, (2011) reports that all perpetrators of child sexual abuse were adult males known to, and resident in the neighbourhood of their victims. Envuladu, Umaru, Banwat, Lar, Lassa, and Zoakah (2013) found that in 
Jos Plateau state Nigeria, 51 (63.8\%) of sex offenders were mostly known to the victims, most of which were friends $(41.2 \%)$ and neighbours $(37.3 \%)$, others were cousins, uncles and brothers $(21.5 \%)$.

Responses to childhood and adulthood sexual violence are complex and highly individualized. Some survivors experience severe and chronic psychological symptoms, whereas others experience little or no distress. Childhood sexual trauma is associated with posttraumatic stress disorder (PTSD), depression, suicide, alcohol problems, eating disorders, low sexual interest, relationship difficulties, high-risk sexual behaviours and extreme coping strategies (Yuan, Koss, \& Stone, 2006). Adolescents with a history of child sexual abuse demonstrate a three to fourfold increase in rates of substance abuse/dependence (Kilpatrick, Ruggiero, Acierno, Saunders, Resnick, \& Best, 2003). Signs that a child may be suffering sexual abuse include: social withdrawal, depression and suicidal ideation, eating disorders, anxiety, risktaking behaviour (such as running away, self-harming, drug and alcohol misuse), expensive new gifts, reluctance to spend time with specific individuals, using sexually explicit language that is not usual for a child their age (Goodyear-Brown, 2012). The incidence of reported child sexual abuse is on the increase in Suleja, Niger state Nigeria, a total of 81 cases of sexual abuse were recorded, where children (77 cases) accounted for $95.1 \%$ of the cases. There were 41 cases of sexual abuse seen in 2007, while 40 cases were documented within the first half of 2008 (Abdulkadir, Umar, Musa, Musa, Oyeniyi, Ayoola-Williams, \& Okeniyi, 2011).

Meta-analysis indicates that the average benefit of psychotherapy is .85 standard deviation units (Smith \& Glass, 1977). According to Cully and Teten (2008), cognitive behavioural therapy (CBT) builds a set of skills that enables an individual to be aware of thoughts and emotions; identify how situations, thoughts, and behaviours influence emotions; and improve feelings by changing dysfunctional thoughts and behaviours. While, cognitive restructuring is aimed at changing a pattern of thought that is presumed to be causing a disturbed emotion or behavior. About 75 percent of people gain some improvement from therapy. Therapy also seems to be more helpful than a placebo or the passage of time (Kring, Johnson, Davidson \& Neale, 2010). Using 5D's (Delay, Distract, Deep Breath, Drink Water and Discuss) in thought stopping Saleh (2016), found that the 5D's were effective in managing cravings, for anger, sexual immorality, manipulation, stealing, lying and masturbation among persons with substance abuse problem, with delay and distract as the most preferred D's, followed by Discuss, deep breath and drink water respectively. Osadan and Reid, (2015) report that up to $95 \%$ of child molestations can be prevented, talking to children honestly and from an early age about not letting others touch their private parts and telling them that it is appropriate to tell an adult if someone tries, can go a long way to stopping this social problem.

Considering the aforementioned effects of sexual abuse, the problem identified in this study is to assess the effects of sexual abuse in a lady 14 years after the incidence. The study is thus aimed at assessing the effects of sexual abuse and the efficacy of psychotherapy in treating psychological distress associated with sexual abuse. The study is therefore designed to answer two research questions;

1. Will the victim of child sexual abuse 14 years after come down with psychological distress?

2. Will psychotherapy be effective in treating psychological distress in a sexually abuse lady 14 years after?

\section{Method}

\subsection{Design}

Single case pre/post- test experimental design utilizing a mixed method using qualitative and quantitative approach was utilized in this study.

\subsection{Sampling Technique/Participant}

Convenience sampling technique was employed in recruiting a 22 year old undergraduate student of Plateau state University Bokkos. The study reports the ordeal of a lady who was sexually abused between ages 7 and 9 .

Participant's ordeal: "One of my father's 'spiritual sons' who has issues with accommodation was offered a place to stay in our house. He helps my parents in bringing me and my siblings from school. 
Come get sweets was the usual of this man whenever, he brings us back from school, he always gave me more sweets than my other siblings so I always hanged around him until about 4:00 - 5:00PM when my mum would be back from work. The usual of 'Uncle' as we called him, was come get sweets as he helped me to undress my uniform. In the year 2002 when I was 7 years old, the story changed, come get sweets as usual. However, one faithful day, my siblings rushed in collected and rushed out gladly with their sweets, it was siestas time at about 2:00PM, 'Uncle' asked me to sleep in his room, as innocent as sleeping in 'Uncle's' room sounded and seemed, I rushed to his bed. He started tickling me, I was laughing aloud but he said I should not wake my siblings who were already sleeping. He brought a whole lot of candy, sweets, and biscuit and asked if I wanted some, I nodded and he told me to lay straight on the bed, I did as I was desperate for the candies. He started touching me unusually and breathing heavily, I was scared and thought he want to cry, I had no idea of what was going on. He asked me to open my legs, which I did innocently and he started pulling my pant, I was scared, and started crying, but he told me to keep quiet if not he will beat me for disturbing my siblings and that he will not give me more sweets. I managed to keep quite but I did not like the way uncle was rubbing my private part. He made way for his zippers unlocked and forced himself on me, it was very hurtful but he kept forcing himself until I could shout no more, I became weak and unconscious. When mum returned from work I was silent because he threatened to kill me if I say anything to anyone, mum thought I was sick she gave me some tablets to take. Mum was always busy having papers on her table and I had lesser image of dad because he was always busy too. I was breaking down day by day; I lost my childhood cheerfulness to a man who was about 25 years older than me. The sexual abuse went on and on, it became a habit, the abuse continued until I was 9 years old. One faithful day, mum came back from work early; she came to 'Uncle's' room and the sight of 'Uncle' on me made her collapsed. After the incidence, I was rushed to the hospital and uncle was sent out of the house. The incidence made my mum resigned her work and stayed at home with us since then. I grew up with this story and I have tried all my life to forget, but it won't go."

\subsection{Measures}

Symptom Distress Checklist 90 (SCL- 90); developed by Derogatis, Lipman and Covi (1977), restandardized for Nigerian use by Omoluabi (1996) was to assess 10 primary categories of symptoms associated with distress. The age range for Nigerian university students is $18-26$ years (Onighaiye, 1996) and adults, 26 - 87 years old (Erinoso, 1996). Derogatis et al (1977) reported alpha coefficients which ranged from .77 for psychoticism to .90 for depression. Week interval test- retest reliability coefficients ranged from .78 for hostility to .90 for phobic anxiety. Erinoso (1996) reported significant coefficients of concurrent validity between retirement, stress inventory and SCL- 90 scales which ranged from .26 for hostility scale to .47 for neuroticism scale.

The Posttraumatic Stress Disorder Checklist - Specific (PCL-S); developed by Weathers, Litz, Huska and Keane (1993) was used for data collection. The scale is a 17 item self- report measure rated on a 5 point severity scale. PCL - S (specific) is a non military version that can be referenced to any specific traumatic event (US department of veteran Affairs, National Centre for PTSD, 2010). Internal coefficient of the instrument were very high for the total scale (.97) and for each subscale (.92 - .93). Test- re-test reliability over $2-3$ days was .96. Blanchard, Alexander, Buckley, and Forneris (1996) found that a score of 44 (rather than 50) maximized diagnostic efficiency of .90. Ventureya, Yao, Cottraux, Note, and De Mey-Guillard (2002) reported excellent internal consistency (.86) and test-retest reliability (.80) for the total PCL-S Score. Using the cut off point of 44 recommended by Blanchard et al (1996), the PCL-S showed a sensitivity of .97, a specificity of .87 , and an overall diagnostic efficacy of .94

Beck Depression Inventory (BDI-II); developed by Beck (1996) is a 21-item self-report instrument designed to assess the severity of depression in adults and adolescents aged 13 years and older. The BDI-II was designed to act as an indicator of depressive symptoms based on diagnostic criteria in the $D S M$ - $I V$. The 21 items are self-rated on a 4-point scale ranging from 0 to 3 . Total raw scores can range from 0 to 63 , and are then converted into descriptive classifications based on cut-off scores. Total score of 0-13 is considered minimal range, 14-19 is mild, 20-28 is moderate, and 29- 63 is severe (Community- University Partnership for the Study of Children, Youth and Families, 2011). Wang and 
Gorenstein (2013) reported the internal consistency of BDI-II as around 0.9 and the retest reliability ranged from 0.73 to 0.96 .

Beck Hopelessness Scale (BHS); BHS is a 20 item scale for measuring the extent of negative attitudes about the future (optimism) as perceived by adolescents and adults (Beck, Weissman, Lester, \& Trexler, 1974). Research reported by Durham (1982) indicates that reliability may be lower in college students $(\mathrm{KR}-20=.65)$. Pearson product-moment correlation between the test- retest scores was .69 $(\mathrm{P}<.001)$ (Beck, \& Steer, 1993). Beck, Shuyler, and Herman (1974) examined the relationship between clinical ratings of hopelessness and BHS scores. The correlations with the clinical ratings of hopelessness were $.74(\mathrm{p}<.001)$ in the general practice sample and $.62(\mathrm{p}<.005)$ in the attempted suicide sample. The interrater reliability of two judges was $.86(\mathrm{p}<.001)$.

\subsection{Procedure}

This study lasted for 13 weeks (sessions). Session 1; focused on history taking (utilizing qualitative approach), session 2 and 3; psychological assessment (Pre- test), session 4; insight orientation therapy and thought stopping, the client was trained on how to apply the 5D's (Delay, Distract, Deep Breath, Drink Water and Discuss) in managing cravings for masturbation, client was also trained on self monitoring technique so as to enable her record the number of times she masturbates each week. Session 5; client centred therapy and psychoeducation with emphasis on psycho-educating client based on the results of her assessment, session 6, 7 and 8; focused on CBT with emphasis on cognitive restructuring and application of 5D's in managing cravings for masturbation, session 9; self monitoring and self evaluation, session 10; all instruments of data collection were re-administered, session 11 and 12; CBT in order to address significant areas based on result of the post- test assessment (results of the pre and post-test were compared). Session 13 self evaluation, progress report and conclusion.

\subsection{Data Analysis}

All data were manually analysed, client's raw scores on each of the instrument of data collection were compared with the mean scores and or cut-off points of the instruments of data collection. Scores higher than the mean score and or cut-off point points indicates significance while scores lower than the mean score and or cut-off points are not significant.

\section{Result}

Research question 1: Will the victim of child sexual abuse 14 years after come down with psychological distress?

At assessment using qualitative approach, participant reported that she develops the following problems since her sexual abuse experience; hatred, anger, self-pity, thoughts of killing herself, low selfesteem, unsociable, fear and lack of trust for men, which results to poor interpersonal relationship with males, less concentration in class if it was a male teacher. She experiences, fear of being naked, fear of sex in the future which mostly comes as an irresistible thought, this makes her hold on to the belief that she will not marry in the future, she dreams about sex approximately 4 times a month, whenever, participant experience this she masturbates.

Pre-test results as indicated on tables 1, 2, 3, and 4 answered the first research question; will the victim of child sexual abuse 14 years after come down with psychological distress? Based on assessment using SCL - 90; Result indicates that participant had higher levels of psychological distress on 9 subscales out of the 10 sub scales of SCL - 90 with the total mean score of 218 which is above the total mean score of 108.31. Depression with the raw score of 40 (Mean 17.55) has the highest significance, followed by anxiety with 31 (Mean 10.66), Interpersonal sensitivity with 29 (Mean 12.51), Obsessive compulsive 23 (Mean 14.95), Phobic anxiety 23 (4.95), psychoticism 21 (Mean 7.61), paranoid ideation 17 (Mean 4.95), and Neuroticism 11 (Mean 7.61), Hostility on the significant scales had the lowest significant score of 10 (Mean 8.44). On PCL - S, participant's score of 54 is above the cut-off score of 44 indicating the diagnosis of posttraumatic stress disorder. Participants score of 28 on Beck depression inventory falls within the range of 21 - 30 indicating moderate level of depression. While on Beck 
hopelessness scale, participant score of 5 falls within the score range of 4 - 8 indicating mild level of hopelessness.

Table 1. Showing pre and post test results of participant on symptom distress check list -90 (SCL - 90)

\begin{tabular}{lllll}
\hline Instrument & Pre- test & \multicolumn{3}{l}{ Post- test } \\
\hline SCL - 90 & Raw score & Mean score & Raw score & Mean score \\
& & & & \\
\cline { 2 - 5 } Somatization & 13 & 14.96 & 1 & 14.96 \\
Obsessive compulsive & 23 & 14.95 & 21 & 14.95 \\
Interpersonal sensitivity & 29 & 12.51 & 17 & 12.51 \\
Depression & 40 & 17.55 & 16 & 17.55 \\
Anxiety & 31 & 10.66 & 9 & 10.66 \\
Hostility & 10 & 8.44 & 3 & 8.44 \\
Phobic anxiety & 23 & 4.95 & 7 & 4.95 \\
Paranoid ideation & 17 & 4.95 & 16 & 4.95 \\
Psychoticism & 21 & 7.95 & 4 & 7.95 \\
Neuroticism & 11 & 7.61 & 6 & 7.61 \\
TOTAL SCORE & $\mathbf{2 1 8}$ & $\mathbf{1 0 8 . 3 1}$ & $\mathbf{1 0 0}$ & $\mathbf{1 0 8 . 3 1}$ \\
\hline
\end{tabular}

Table 2. Showing pre and post test results of participant on posttraumatic stress disorder checklist-specific (PCL-S)

\begin{tabular}{lllll}
\hline Instrument & Pre - test & \multicolumn{2}{l}{ Post - test } \\
\hline & Raw score & Cut-off score & Raw score & Cut - off score \\
\cline { 2 - 5 } PCL - S & 54 & 44 & 32 & 44 \\
\hline
\end{tabular}

Table 3. Showing pre and post test results of participant on Beck depression inventory II (BDI - II)

\begin{tabular}{lllll}
\hline Instrument & Pre - test & \multicolumn{3}{c}{ Post - test } \\
\hline & Raw score & Score range & Raw score & Score range \\
\cline { 2 - 5 } BDI - II & 28 & $21-30$ & 9 & $0-10$ \\
\hline
\end{tabular}

Table 4. Showing pre and post test results of participant on Beck hopelessness scale (BHS)

\begin{tabular}{lllll}
\hline Instrument & Pre - test & \multicolumn{3}{c}{ Post - test } \\
\hline \multirow{3}{*}{ BHS } & Raw score & Score range & Raw score & Score range \\
\cline { 2 - 5 } & 5 & $4-8$ & 0 & $0-3$ \\
\hline
\end{tabular}

Research question 2: Will psychotherapy be effective in treating psychological distress in a sexually abuse lady 14 years after?

Result of the post-test assessment answered the second research question indicating that psychotherapy is effective in treating the psychological distress associated with sexual abuse. Participant scores on all instruments used in assessment reduced after psychotherapy session (post- test). On SCL90; only 3 subscales were significant, all scores of the post-test are below the scores of the pre-test; Obsessive compulsive scale with the score of 21 , Interpersonal sensitivity with the score of 17 , and the score of 16 on paranoid ideation scale. The total SCL-90 score of 100 is below the mean score of 108.31 . On PCL- S participants score of 32 is below the cut-off score of 44 which is indicative of the absence of PTSD. Participant's score of 9 on Beck depression inventory falls within the score range of 0-10 which indicates normal levels of depression, and finally on Beck hopelessness scale participant had 0, indicating the absence of hopelessness (see tables 1, 2, 3, and 4).

In line with the result of the post- test, participant reported her progress after psychotherapy thus: "I was abused sexually as a child. I struggled with a lot of issues that weighed me down as a result of the experience. I was living in a shadow not a life. I got to start psychotherapy with one of the psychology 
lecturers. I was reluctant because it was a male, but I just felt I wanted to live a life and for that to happen, I needed to give help a chance whether it's coming from a male or female. I underwent the sessions successfully and it has redefined life, I am not worthless after all, my self esteem is healthy, I concentrate in class with no discrimination. I relate healthily with males, with the help of psychotherapy I believe there is a life after abuse, it doesn't end there..."

\section{Discussion}

This study investigates psychological distress associated with child sexual abuse and the efficacy of psychotherapy in treating the psychological distress associated with sexual abuse. Findings of this study based on pre- test result revealed that; Participant due to her experience of sexual abuse had significant levels of depression, anxiety, interpersonal sensitivity, obsessive compulsive, phobic anxiety, psychoticism, paranoid ideation, neuroticism, hostility, posttraumatic stress disorder, and hopelessness. Result of this study is in-line with results of earlier studies reported by Yuan et al (2006), and Goodyear-Brown (2012). Other psychological distresses associated with sexual abuse as reported by clients are, hatred, anger, self pity, thoughts of killing herself, low self- esteem, unsociable, fear and lack of trust for men, which results to poor interpersonal relationship with males, less concentration in class if it was male teacher, fear of being naked, fear of sex in the future which mostly comes as an irresistible thought, this makes her to hold on to the belief that she will not marry in the future, she dreams about sex approximately 4 times a month, whenever, participant experience this she masturbates.

Result of the post-test assessment answered the second research question; finding of this study indicates that psychotherapy is effective in treating psychological distress associated with sexual abuse. Participant's raw scores on all psychological instruments administered at assessment reduced after psychotherapy sessions. On SCL-90; only 3 subscales (Obsessive compulsive, Interpersonal sensitivity and Paranoid ideation) were significant with lower raw scores compared to 9 subscales that were significant at pre-test. The total SCL-90 score of 100 is below the mean score of 108.31 and the pre-test score of 218. On PCL- S participants score of 32 is below the cut-off score of 44 . This implies the absence of posttraumatic stress disorder, participant's scores on Beck depression II falls within the normal level of depression and finally on Beck hopelessness scale participant had 0 which falls within the score range of 0-3 indicating minimal level of hopelessness. Result of this study is in line with earlier studies that reported the efficacy of cognitive behaviour therapy in treating psychological distress, Saleh, (2016) using cognitive behaviour therapy reported that the 5D's are effective in managing cravings, for anger, sexual immorality, manipulation, stealing, lying and masturbation among persons with substance abuse problem, with delay and distract as the most preferred D's, followed by discuss, deep breath and drink water.

\section{Conclusion}

Pre- test result revealed that; depression, anxiety, interpersonal sensitivity, obsessive compulsive, phobic anxiety, psychoticism, paranoid ideation, neuroticism, hostility, posttraumatic stress disorder, and hopelessness, are psychological distress associated with sexual abuse. Others issues associated with sexual abuse are feeling of hatred, anger, self pity, thoughts of killing one's self, low self- esteem, being unsociable, fear and lack of trust for men, poor interpersonal relationship with males, less concentration in class if it was male teacher, fear of being naked, fear of sex in the future, negative belief that one cannot marry, dreams about sex, and masturbation. Result of post-test assessment revealed that psychotherapy is effective in treating psychological distress associated with sexual abuse. Therefore, the researcher concludes that, parents and care givers should be cautions of those who take care of their wards and the child act right should be implemented in all states of the federation. There is the need for awareness in schools and among women groups on sexual abuse among children. Further studies should be carried in this area among primary school pupils so as to identify those who have been abused at an early stage.

\section{References}


1. Abdulkadir, I., Musa, H. H., Umar, L. W., Musa, S., Jimoh, W.A. Na'uzo, A. M., (2011). Child Sexual Abuse in Minna, Niger State Nigeria. Nigerian Medical Journal. Vol. 52 Issue 2

2. Abdulkadir, I., Umar, L. W., Musa, H. H., Musa, S., Oyeniyi, O. A., Ayoola-Williams, O. M., \& Okeniyi, L. (2011). Child sexual abuse: A review of cases seen at general hospital Suleja, Niger state. Ann Nigerian Med;5:15-9

3. Beck, A. T., Shuyler, D., \& Herman, I. (1974). Development of suicide intent scales. In A. T., Beck, H. L. P. Resnik, \& D. J. Lettieri (Eds), The Prediction of Suicide (pp. 45-56). Bowie, MD: Charles Press

4. Beck, A. T., Weissman, A., Lester, D., \& Trexler, L. (1974). The measurement of pessimism: the hopelessness scale. Journal of Consulting and Clinical Psychology, 42, 861-865

5. Blanchard, E. B., Jones-Alexander, J., Buckley, T. C., \& Forneris, C. A. (1996). Posttraumatic stress disorder among patients with or facial pain. Journal of Orofacial pain, 19, 309-317.

6. Community- University Partnership for the Study of Children, Youth and Families (2011). Review of the Beck Depression Inventory $2^{\text {nd }}$ Edition (BDI-II). Edmonton, Alberta, Canada.

7. Cully, J. A., \& Teten, A. L. (2008). A therapist's guide to brief cognitive behavioural therapy. Department of Veterans affairs, South Central mental illness research education research (MIRECC), Houston.

8. Derogatis, L. R., Lipman, R. S., \& Covi, L., (1977). SCL-90R: administration, scoring and procedures manual. Baltimore, John Hopkins University School of medicine, clinical psychometrics research Unit.

9. Durham, T. W. (1982). Norms, reliability and item analysis of the hopelessness scale in a general psychiatric, forensic psychiatric and college populations. Journal of Clinical Psychology, 38, 497-600.

10. Envuladu, E. A., Umaru, R. J., Banwat, M. E., Lar, L. A., Lassa, S., Zoakah, A. I., (2013). Sexual abuse among female secondary school students in Jos, North Central Nigeria. Journal of Medicine in the Tropics. Vol 15, No 1

11. Erinoso, O. A., (1996). The source of Stress among Nigerian retirees. In omoluabi, (1997) manual series editor. Department of Psychology University of Lagos, Nigeria.

12. Finkelhor, D. (2012). Characteristics of crimes against juveniles. Durham, NH: Crimes against Children Research Centre.

13. Goldman, R. J., \& Goldman, J. D. G.m (1988). The prevalence and nature of child sexual abuse in Australia, Australian Journal of Sex, Marriage and Family, Volume 9, Issue 2. DOI: 10.1080/01591487.1988.11004405

14. Goodyear-Brown, P. (ed.) (2012) Handbook of child sexual abuse: identification, assessment and treatment. Hoboken, New Jersey: Wiley.

15. Kendall-Tackett, K., (2001). The long shadow: Adult survivors of childhood abuse. Chapter from: The hidden feelings of motherhood: Coping with mothering stress, depression and burnout. Oakland, CA: New Harbinger, 2001

16. Kenneth S. Kendler, M.D., et al, (2000). Medical college of Virginia Commonwealth University, Archives of General Psychiatry; 57:953-959.

17. Kilpatrick, D. G., Ruggiero, K. J., Acierno, R., Saunders, B. E., Resnick, H. S., \& Best, C. L. (2003). Violence and risk of PTSD, major depression, substance abuse/dependence, and comorbidity: Results from the National survey of adolescents. Journal of Consulting and Clinical Psychology, 71, 692-700.

18. Kring, A. M., Johnson, S. L., Davidson, G. C., \& Neale, J. M. (2010 ). Abnormal psychology. (11 ${ }^{\text {th }}$ Edition). John Wiley \& Sons, Inc.

19. Miller, T. R., Cohen, M. A., \& Wiersema, B. (1996). Victim costs and consequences: A new look. U.S. Department of Justice, Office of Justice Programs, National Institute of Justice: NCJ 155282

20. National Center for Juvenile Justice (2001) Sexual assault of young children as reported to law enforcement: Victim, incident, and offender characteristics. www.ojp.usdoj.gov/bjs/pub/pdf/saycrle.pdf

21. Omoluabi, P. F., (1996). Development of retirement Stress inventory (PSI). Unpublished manuscript. Department of Psychology, University of Lagos.

22. Onighaye, M. A., (1996). The impact of the length of time in the university on ego identity, self esteem and stress manifestation in students. Unpublished B.Sc Thesis, psychology Department, University of Lagos.

23. Osadan, R., \& Reid, E., (2015). Child sexual abuse and sexual aggression in children. International Journal of Humanities and Social Science, Vol. 5, No. 6(1)

24. Saleh, D. A. (2016). Application of 5D's in managing cravings for substance abuse. Researchjournali's Journal of Public Health Vol. 2, No. 4 
25. Smith, M. L., \& Glass, G. V. (1977). Meta-analysis of psychotherapy outcome studies. American Psychologist, 32(9), 752-760.

26. Townsend, C., \& Rheingold, A.A., (2013). Estimating a child sexual abuse prevalence rate for practitioners: studies. Charleston, S.C., Darkness to Light. Retrieved from www.D2l.org retrieved 1/5/2016

27. Wang, Y., \& Gorenstein, C. (2013). Psychometric properties of the Beck depression inventory- II: a comprehensive review. Revista Brasileira de Psiquiatria. 35:416-431. Doi:10.1590/1516-4446-2012-1048

28. Weathers, F. W., Litz, B. T., Herman, D. S., Huska, J. A. \& Keane, T. M. (1993) The PTSD Checklist (PCL): Reliability, validity, and diagnostic utility. Paper presented at the 9th Annual Conference of the ISTSS, San Antonio

29. Whealin, J. (2007). "Child sexual abuse". National centre for post traumatic stress disorder, US Department of Veterans Affairs.

30. Yuan, N.P., Koss, M.P., \& Stone, M. (2006, March). The psychological consequences of sexual trauma. Harrisburg, PA: VAWnet, a project of the National Resource Centre on Domestic Violence. Retrieved from: http://www.vawnet.org retrieved on the 16/5/2016 